Pacific Journal of Mathematics

THE UNIFORMIZING FUNCTION FOR A CLASS OF RIEMANN 


\title{
THE UNIFORMIZING FUNCTION FOR A CLASS OF RIEMANN SURFACES
}

\author{
J. E. KIRK, JR.
}

\begin{abstract}
This paper considers a class of simply connected Riemann surfaces which are shown to be of parabolic type. Infinite product representations are obtained for both the uniformizing function and its derivative.
\end{abstract}

The class of surfaces. For each integer $n \geqq 1$ let $\left[a_{2 n-1}, b_{2 n-1}\right]$ and $\left[b_{2 n}, a_{2 n}\right]$ denote closed intervals of the real line satisfying $0<$ $a_{2 n-1}<b_{2 n-1}<b_{2 n}$ and $b_{2 n+1}<b_{2 n}<a_{2 n}$. Let $S_{n}$ denote a copy of the $w$-sphere. Slit $S_{1}$ along $\left[a_{1}, b_{1}\right]$, slit $S_{2 n}$ along both $\left[a_{2 n-1}, b_{2 n-1}\right]$ and $\left[b_{2 n}, a_{2 n}\right]$, and slit $S_{2 n+1}$ along $\left[a_{2 n+1}, b_{2 n+1}\right]$ and $\left[b_{2 n}, a_{2 n}\right]$. A surface $F$ belonging to the class is constructed by joining $S_{2 n-1}$ to $S_{2 n}$ along $\left[a_{2 n-1}, b_{2 n-1}\right]$ and $S_{2 n}$ to $S_{2 n+1}$ along $\left[b_{2 n}, a_{2 n}\right]$ with the intervals forming first order branch lines.

The uniformizing function. $F$ is a simply connected, open Riemann surface and is thus either parabolic or hyperbolic. There is a unique analytic one-to-one mapping $f(z)$ which maps $\{|z|<r \leqq \infty\}$ onto $F$ and satisfies $f(0)=0 \in S_{1}$ and $f^{\prime}(0)=1$. An argument similar to that in [2, p. 1137] shows that $f(z)$ is real if $z$ is real. For notation let $f\left(\delta_{k}\right)=0 \in S_{k}, f\left(\gamma_{k}\right)=\infty \in S_{k}, f\left(\alpha_{k}\right)=a_{k}$ and $f\left(\beta_{k}\right)=b_{k}$. The image of $S_{1}$ under $f^{-1}(z)$ is a region containing the origin and bounded by a Jordan curve $C_{1}$ which is symmetric about the real axis. For $n>1$ the image of $S_{n}$ is an annular region about the origin bounded by two Jordan curves, $C_{n-1}$ and $C_{n}$, each symmetric about the real axis. For $n \geqq 1, C_{n}$ intersects the real axis at $\alpha_{n}$ and $\beta_{n}$ only. Furthermore,

$$
\beta_{n+1}<\beta_{n}<\gamma_{1}<0<\alpha_{2 n-1}<\delta_{2 n}<\gamma_{2 n}<\alpha_{2 n}<\gamma_{2 n+1}<\delta_{2 n+1}<\alpha_{2 n+1} \text {. }
$$

The closed surfaces and rational functions. Let $F_{n}$ denote the surface formed from the first $2 n$ sheets of $F$ with the cut along $\left[b_{2 n}\right.$, $a_{2 n}$ ] on $S_{2 n}$ deleted. $F_{n}$ is an elliptic surface so there is a unique rational function $R_{n}(z)$ mapping the $z$-sphere one-to-one and onto $F_{n}$ which satisfies $R_{n}(0)=0 \in S_{1}, R_{n}(\infty)=\infty \in S_{2 n}$ and $R_{n}^{\prime}(0)=1$. For notation let $R_{n}\left(\delta_{k, n}\right)=0 \in S_{k}, R_{n}\left(\gamma_{k, n}\right)=\infty \in S_{k}, R_{n}\left(\alpha_{k, n}\right)=\alpha_{k}$ and $R_{n}\left(\beta_{k, n}\right)=$ $b_{k}$. Also, throughout the following the notation $1-z / \alpha_{\phi}=\alpha_{\phi}^{*}, 1-$ $z / \beta_{\phi}=\beta_{\phi}^{*}, 1-z / \gamma_{\phi}=\gamma_{\phi}^{*}$ and $1-z / \delta_{\phi}=\delta_{\phi}^{*}$ is used. Then

$$
R_{n}(z)=\left[z / \gamma_{1, n}^{*}\right] \prod_{k=2}^{2 n-1}\left[\delta_{k, n}^{*} / \gamma_{k, n}^{*}\right] \delta_{2 n, n}^{*}
$$


and

$$
R_{n}^{\prime}(z)=\prod_{k=1}^{2 n-1}\left[\alpha_{k, n}^{*} \beta_{k, n}^{*} /\left(\gamma_{k, n}^{*}\right)^{2}\right]
$$

since $R_{n}(z)$ and $R_{n}^{\prime}(z)$ must contain exactly these factors. The zeros and poles of $R_{n}(z)$ and the points corresponding to the branch points of $F_{n}$ are real and their ordering is similar to that for $f(z)$.

\section{LemMa $1 . \quad F$ is parabolic.}

Proof. Let $D_{n}$ be the plane with $\left(-\infty, \beta_{2 n-1 n}\right]$ on the real axis deleted. Let $\Delta_{n}$ be the domain in the plane which is the interior of the curve $C_{2 n}$ excluding the segments $\left[\beta_{2 n}, \beta_{2 n-1}\right]$ and $\left[\gamma_{2 n}, \alpha_{2 n}\right]$. Then $\psi_{n}(z)=f^{-1}\left[R_{n}(z)\right]$ maps $D_{n}$ onto $A_{n}$. An argument similar to that in $[2$, p. 1138] shows that $F$ cannot be hyperbolic so that $F$ is parabolic. Thus $f(z)$ maps the plane onto $F$. Furthermore, the sequence $\left\{D_{n}\right\}$ converges to its kernel which is the plane.

LeMma 2. $R_{n}(z) \rightarrow f(z)$ subuniformly (uniformly on compact subsets) in the plane as $n \rightarrow \infty$. Furthermore, $\delta_{k, n} \rightarrow \delta_{k}, \gamma_{k, n} \rightarrow \gamma_{k}, \alpha_{k, n} \rightarrow$ $\alpha_{k}$ and $\beta_{k, n} \rightarrow \beta_{k}$ as $n \rightarrow \infty$.

Proof. Since the sequences of domains $\left\{D_{n}\right\}$ and $\left\{\Delta_{n}\right\}$ converge to their kernels which in both cases is the plane then the sequence $\left\{f^{-1}\left[R_{n}(z)\right]\right\}$ converges subuniformly in the plane [3, p. 18] to the identity. Hence $R_{n}(z) \rightarrow f(z)$ subuniformly in the plane. It follows from Hurwitz's theorem that $\delta_{k, n} \rightarrow \delta_{k}, \gamma_{k, n} \rightarrow \gamma_{k}, \alpha_{k n} \rightarrow \alpha_{k}$ and $\beta_{k, n} \rightarrow$ $\beta_{k}$ as $n \rightarrow \infty$.

Lemma 3. The infinite product

$$
\Pi(z)=\left(z / \gamma_{1}^{*}\right) \prod_{k=2}^{\infty}\left(\delta_{k}^{*} / \gamma_{k}^{*}\right)
$$

converges subuniformly in the plane.

Proof. Since $\delta_{k} \rightarrow \infty$ and $\gamma_{k} \rightarrow \infty$ as $k \rightarrow \infty$ then if $R>0$ there is an integer $n_{0}=n_{0}(R)>1$ such that for $k \geqq n_{0}-1$ both $\delta_{k}>R$ and $\gamma_{k}>R$. Thus, $\log \left[\delta_{k}^{*} / \gamma_{k}^{*}\right]$ is defined for $|z| \leqq R$. Since for $k \geqq 1$, $0<\delta_{2 k}<\gamma_{2 k}<\gamma_{2 k+1}<\delta_{2 k+1}$, then for $n \geqq 0, p \geqq 0$ and $|z| \leqq R$,

$$
\begin{array}{r}
\left|\sum_{k=n_{0}+n}^{n_{0}+n+p} \log \left(\delta_{k}^{*} / \gamma_{k}^{*}\right)\right|=\left|\sum_{m=1}^{\infty}\left(z^{m} / m\right) \sum_{k=n_{0}+n}^{n_{0}+n+p}\left(1 / \gamma_{k}^{m}-1 / \delta_{k}^{m}\right)\right| \\
\leqq \sum_{m=1}^{\infty}\left(R / \delta_{n_{0}+n-1}\right)^{m}=R /\left(\delta_{n_{0}+n-1}-R\right) .
\end{array}
$$


Because $R /\left(\delta_{n_{0}+n-1}-R\right) \rightarrow 0$ as $n \rightarrow \infty$ then the uniform Cauchy criterion is satisfied in $|z| \leqq R$ by the infinite series $\sum_{k=n_{0}}^{\infty} \log \left[\delta_{k}^{*} / \gamma_{k}^{*}\right]$. This is sufficient for $\Pi(z)$ to converge subuniformly in the plane.

\section{LEMMA 4. $\Pi(z)=f(z)$.}

Proof. Because $\gamma_{k, n} \rightarrow \gamma_{k}$ and $\delta_{k, n} \rightarrow \delta_{k}$ as $n \rightarrow \infty$ there exists $R>$ 0 and $N>0$ such that if $n>N$ and $|z| \leqq R$ the quotient $R_{n}(z) / \Pi(z)$ is nonzero and analytic with value 1 at $z=0$. Thus, using the principal value of the logarithm,

$$
\begin{aligned}
\log \left[R_{n}(z) / \Pi(z)\right] & =\log \left(\gamma_{1}^{*} / \gamma_{1, n}^{*}\right)+\sum_{m=1}^{\infty} c_{m} z^{m} \text { where for } 2<p \leqq 2 n-1 \\
c_{m}=c_{m}(n)= & \frac{1}{m}\left[1 / \delta_{2 n, n}^{m}+\sum_{k=2}^{p-1}\left(1 / \gamma_{k}^{m}-1 / \delta_{k}^{m}-1 / \gamma_{k, n}^{m}+1 / \delta_{k, n}^{m}\right)\right. \\
+ & \left.\sum_{k=p}^{\infty}\left(1 / \gamma_{k}^{m}-1 / \delta_{k}^{m}\right)-\sum_{k=p}^{2 n-1}\left(1 / \gamma_{k, n}^{m}-1 / \delta_{k, n}^{m}\right)\right]
\end{aligned}
$$

Because

$$
\left|\sum_{k=p}^{\infty}\left(1 / \gamma_{k}^{m}-1 / \delta_{k}^{m}\right)\right|<1 / \delta_{p-1}^{m}
$$

and

$$
\left|\sum_{k=p}^{2 n-1}\left(1 / \gamma_{k, n}^{m}-1 / \delta_{k, n}^{m}\right)\right|<1 / \delta_{p-1, n}^{m}
$$

then $\left|c_{m}(n)\right| \leqq\left|1 / \delta_{2 n, n}^{m}\right|$

$$
+\left|\sum_{k=2}^{p-1}\left(1 / \gamma_{k}^{m}-1 / \delta_{k}^{m}-1 / \gamma_{k, n}^{m}+1 / \delta_{k, n}^{m}\right)\right|+1 / \delta_{p-1}^{m}+1 / \delta_{p-1, n}^{m} .
$$

This bound for $c_{m}(n)$ has limit $2 / \delta_{p-1}^{m}$ as $n \rightarrow \infty$ and $2 / \delta_{p-1}^{m} \rightarrow 0$ as $p \rightarrow$ $\infty$. Hence $c_{m}(n) \rightarrow 0$ as $n \rightarrow \infty$. The convergence of $\left\{\log \left[R_{n}(z) / \Pi(z)\right]\right\}$ is subuniform in the plane and $\gamma_{1, n} \rightarrow \gamma_{1}$ as $n \rightarrow \infty$. Thus, as $n \rightarrow \infty$, $\lim \log \left[R_{n}(z) / \Pi(z)\right]=\log [f(z) / \Pi(z)]=0$ so that $f(z)=\Pi(z)$.

Lemma 5. The sequences $A_{n}=\sum_{k=1}^{2 n-1} 1 / \alpha_{k, n}, B_{n}=\sum_{k=1}^{2 n-1} 1 / \beta_{k, n}$ and $C_{n}=\sum_{k=1}^{2 n-1} 1 / \gamma_{k, n}$ are bounded.

Proof. There is some $R>0$ such that $R_{n}^{\prime}(z) \neq 0$ if $|z| \leqq R$ and thus,

$$
\log R_{n}^{\prime}(z)=\sum_{m=1}^{\infty}\left(z^{m} / m\right) \sum_{k=1}^{2 n-1}\left(2 / \gamma_{k, n}^{m}-1 / \alpha_{k, n}^{m}-1 / \beta_{k, n}^{m}\right) .
$$

Let $\nu=\nu_{n}$ denote the coefficient of $z$ in this series expansion. For $n \geqq 1$ and $k>1,0<\gamma_{k n}<\alpha_{k, n}$ and for $k \geqq 1, \beta_{k_{n}}<0$ so that, $2 / \gamma_{1, n}$ 
$1 / \alpha_{1, n}-\nu_{n}=B_{n}+\sum_{k=2}^{2 n-1}\left(1 / \alpha_{k, n}-1 / \gamma_{k, n}\right)-\sum_{k=2}^{2 n-1} 1 / \gamma_{k, n}<B_{n}<0$. As $n \rightarrow$ $\infty, \log R_{n}^{\prime}(z) \rightarrow \log f^{\prime}(z)$ subuniformly in the plane and thus,

$$
-\infty<\lim \left(2 / \gamma_{1, n}-1 / \alpha_{1, n}-\nu_{n}\right) \leqq \lim \inf B_{n} \leqq 0 .
$$

Hence the sequence $\left\{B_{n}\right\}$ is bounded. The remaining two sequences are bounded below and the inequalities $C_{n}<\nu_{n}+1 / \alpha_{1, n}-1 / \gamma_{1, n}$ and $A_{n}<C_{n}+1 / \alpha_{1, n}-1 / \gamma_{1, n}$ show they are bounded above.

Lemma 6. The series $\sum_{k=1}^{\infty} 1 / \beta_{k}, \sum_{k=1}^{\infty} 1 / \gamma_{k}, \sum_{k=1}^{\infty} 1 / \alpha_{k}$ and $\sum_{k=2}^{\infty} 1 / \delta_{k}$ are convergent.

Proof. Each of these series is monotone. Using Lemma 2 and the notation and results of Lemma 5 it follows for $p \geqq 1$ that as $n \rightarrow \infty$,

$$
-\infty<\lim \inf B_{n} \leqq \lim \sum_{k=1}^{p} 1 / \beta_{k, n}=\sum_{k=1}^{p} 1 / B_{k}<0 .
$$

Thus the first series converges. $\sum_{k=1}^{\infty} 1 / \gamma_{k}$ converges since it is monotone increasing and for $p \geqq 1$ and $n \rightarrow \infty$,

$$
\sum_{k=1}^{p} 1 / \gamma_{k}=\lim \sum_{k=1}^{p} 1 / \gamma_{k, n} \leqq \lim \sup C_{n}<\infty .
$$

The remaining two series have positive terms and are dominated by convergent series since for $k>1,0<1 / \delta_{k+1}<1 / \alpha_{k}<1 / \gamma_{k}$. Thus, they also converge.

Lemma 7. The infinite product

$$
Q(z)=\prod_{k=1}^{\infty}\left[\alpha_{k}^{*} \beta_{k}^{*} /\left(\gamma_{k}^{*}\right)^{2}\right]
$$

converges subuniformly in the plane.

Proof. This follows from Lemma 6.

As a further consequence of Lemma 6 both $Q(z)$ and $\Pi(z)$ may also be expressed as a quotient of products.

Lemma 8. $f^{\prime}(z)=Q(z) \exp (\delta z)$ with $\delta$ real.

Proof. For some $R>0$ both $Q(z)$ and $R_{n}^{\prime}(z)$ are analytic and nonzero in $|z|<R$. Hence, for $|z|<R$,

$$
\begin{aligned}
\log \left[R_{n}^{\prime}(z) / Q(z)\right]= & \sum_{m=1}^{\infty}\left(z^{m} / m\right)\left[\sum_{k=1}^{\infty} 1 / \alpha_{k}\right. \\
& -\sum_{k=1}^{2 n-1} 1 / \alpha_{k, n}^{m}+\sum_{k=1}^{\infty} 1 / \beta_{k}-\sum_{k=1}^{2 n-1} 1 / \beta_{k, n}^{m}-\sum_{k=1}^{\infty} 2 / \gamma_{k}^{m} \\
& \left.+\sum_{k=1}^{2 n-1} 2 / \gamma_{k, n}^{m}\right] .
\end{aligned}
$$


From Lemmas 5 and 6 there exists $M>0$ such that for $n \geqq 1$

$$
\sum_{k=1}^{2 n-1} 1 / \alpha_{k, n}<M \text { and } \sum_{k=1}^{\infty} 1 / \alpha_{k}<M .
$$

Also, for $k \geqq 1$ and $n \geqq 1, \alpha_{k}<\alpha_{k+1}$ and $\alpha_{k, n}<\alpha_{k+1, n}$ so that

$$
k / \alpha_{k}<\sum_{p=1}^{\infty} 1 / \alpha_{p}<M
$$

and

$$
k / \alpha_{k, n}<\sum_{p=1}^{2 n-1} 1 / \alpha_{p, n}<M
$$

Thus, for $p \geqq 1,\left|\sum_{k=p}^{\infty} 1 / \alpha_{k}^{m}-\sum_{k=p}^{2 n-1} 1 / \alpha_{k, n}^{m}\right|$

$$
<\sum_{k=p}^{\infty}(M / k)^{m}+\sum_{k=p}^{\infty}(M / k)^{m}=2 M^{m} \sum_{k=p}^{\infty}(1 / k)^{m} .
$$

This last expression has limit zero as $p \rightarrow \infty$ provided $m \geqq 2$. Thus, for $m \geqq 2$, it follows that as $n \rightarrow \infty$,

$$
\begin{aligned}
\lim \left[\sum_{k=1}^{\infty} 1 / \alpha_{k}^{m}\right. & \left.-\sum_{k=1}^{2 n-1} 1 / \alpha_{k, n}^{m}\right] \\
& =\lim \left[\sum_{k=p}^{\infty} 1 / \alpha_{k}^{m}-\sum_{k=p}^{2 n-1} 1 / \alpha_{k, n}^{m}\right]=0 .
\end{aligned}
$$

Similar arguments show that as $n \rightarrow \infty$ and provided $m \geqq 2$,

$$
\lim \left[\sum_{k=1}^{\infty} 1 / \beta_{k}^{m}-\sum_{k=1}^{2 n-1} 1 / \beta_{k, n}^{m}\right]=\lim \left[\sum_{k=1}^{\infty} 1 / \gamma_{k}^{m}-\sum_{k=1}^{2 n-1} 1 / \gamma_{k, n}^{m}\right]=0 .
$$

Hence, if $\delta$ denotes the limit as $n \rightarrow \infty$ of the coefficient of $z$ in the expansion of $\log \left[R_{n}^{\prime}(z) / Q(z)\right]$ then as $n \rightarrow \infty, \delta z=\lim \log \left[R_{n}^{\prime}(z) / \Pi(z)\right]=$ $\log \left[f^{\prime}(z) / Q(z)\right]$ so that $f^{\prime}(z)=Q(z) \exp (\delta z)$.

\section{Lemma $9 . \quad \delta=0$.}

Proof. Since $Q(z)$ is composed of cannonical products of genus zero then for $\varepsilon>0$ there exists $R>0$ such that if $|z|>R$ and $0<\rho<$ $|\arg z|<\pi-\rho$ then $|Q(z)| \leqq \exp (\varepsilon|z|)$ and $1 /|Q(z)| \leqq \exp (\varepsilon|z|)$. Thus,

$$
\exp (\delta \mathscr{R}(z)-\varepsilon|z|) \leqq\left|f^{\prime}(z)\right| \leqq \exp (\delta \mathscr{R}(z)+\varepsilon|z|) .
$$

Let $V_{1}$ and $V_{2}$ denote open sectors in the first and second quadrants, respectively, with vertex at the origin and sides contained in the open quadrant. If $\delta<0$ and $z \in V_{1}$ then $\mathscr{R}(z)>0$ and there exists $\dot{\phi}_{1}>0$ such that for $|z|>R,\left|f^{\prime}(z)\right| \geqq \exp \left(\phi_{1}|z|\right)$. Let $r_{n}$ denote the distance from the origin to the portion of the curve $C_{n}$ in $V_{1}$ and let $z_{n}$ and $\zeta_{n}$ denote the intersection of $C_{n}$ with the sides of $V_{1}$ where $0<\theta=$ 
$\arg \zeta_{n}-\arg z_{n}$. For $n$ sufficiently large,

$$
\begin{aligned}
b_{2 n+1}- & a_{2 n+1}>f\left(\zeta_{2 n+1}\right)-f\left(z_{2 n+1}\right) \\
& =\int_{z_{2 n+1}}^{\zeta_{2 n+1}} f^{\prime}(z)|d z| \geqq \theta r_{2 n} \exp \left(\phi_{1} r_{2 n}\right)
\end{aligned}
$$

where the integral is along $C_{2 n+1}$. If $n \rightarrow \infty$ then $\theta r_{2 n} \exp \left(\dot{\phi}_{1} r_{2 n}\right) \rightarrow \infty$ and since $a_{2 n+1}>0$ then $b_{2 n+1} \rightarrow \infty$.

However, if $z \in V_{2}$ then $\mathscr{R}(z)<0$ and there exists $\phi_{2}>0$ such that for $|z|>R,\left|f^{\prime}(z)\right| \leqq \exp \left(-\phi_{2}|z|\right)$. It follows that $f(z)$ is bounded in $V_{2}$. If $z \in V_{2}$ and $z \in C_{2 n}$ then $0<b_{2 n}<f(z)$ so that $\left\{b_{2 n}\right\}$ is bounded. This is a contradiction since $b_{2 n+1}<b_{2 n}$. Thus $\delta \leqq 0$. A similar argument shows $\delta \geqq 0$ so that $\delta=0$.

THEOREM. A Riemann surface belonging to the class described is parabolic and a uniformizing function $f(z)$ for a member of the class has the representation

$$
f(z)=\left(z / \gamma_{1}^{*}\right) \prod_{k=2}^{\infty}\left(\delta_{k}^{*} / \gamma_{k}^{*}\right)
$$

The derivative has the representation

$$
f^{\prime}(z)=\prod_{k=1}^{\infty}\left[\alpha_{k}^{*} \beta_{k}^{*} /\left(\gamma_{k}^{*}\right)^{2}\right]
$$

For $k \geqq 1$,

$$
\beta_{k+1}<\beta_{k}<\gamma_{1}<0<\alpha_{2 k-1}<\delta_{2 k}<\gamma_{2 k}<\alpha_{2 k}<\gamma_{2 k+1}<\delta_{2 k+1}<\alpha_{2 k+1} .
$$

Furthermore, $\sum_{k=1}^{\infty} 1 / \alpha_{k}, \sum_{k=1}^{\infty} 1 / \beta_{k}, \sum_{k=1}^{\infty} 1 / \gamma_{k}$ and $\sum_{k=2}^{\infty} 1 / \delta_{k}$ converge.

The author wishes to express his appreciation to Professor H. B. Curtis, Jr. for his suggestions.

\section{REFERENCES}

1. H. B. Curtis, Jr., Some properties of functions which uniformize a class of simply connected Riemann surfaces, Proc. Amer. Math. Soc., 10 (1959), 525-530.

2. - The uniformizing function for certain simply connected Riemann surfaces, Pacific J. Math., 15 (1965), 1137-1144.

3. G. R. MacLane, Riemann surfaces and asymptotic values associated with real entire functions, The Rice Institute Pamphlet (1952).

Received November 30, 1970.

THE UNIVERSITY OF Wyoming 


\section{PACIFIC JOURNAL OF MATHEMATICS}

\section{EDITORS}

\section{H. SAMELSON}

Stanford University

Stanford, California 94305

\section{R. HOBBY}

University of Washington Seattle, Washington 98105

\section{J. DugundJI}

Department of Mathematics University of Southern California Los Angeles, California 90007

RICHARD ARENS

University of California Los Angeles, California 90024

\section{ASSOCIATE EDITORS}
E. F. BECKENBACH
B. H. Neumann
F. WoLF
K. YoSHIDA

\section{SUPPORTING INSTITUTIONS}

UNIVERSITY OF BRITISH COLUMBIA CALIFORNIA INSTITUTE OF TECHNOLOGY

UNIVERSITY OF CALIFORNIA

MONTANA STATE UNIVERSITY

UNIVERSITY OF NEVADA

NEW MEXICO STATE UNIVERSITY

OREGON STATE UNIVERSITY

UNIVERSITY OF OREGON

OSAKA UNIVERSITY

\author{
UNIVERSITY OF SOUTHERN CALIFORNIA \\ STANFORD UNIVERSITY \\ UNIVERSITY OF TOKYO \\ UNIVERSITY OF UTAH \\ WASHINGTON STATE UNIVERSITY \\ UNIVERSITY OF WASHINGTON \\ * * * * \\ AMERICAN MATHEMATICAL SOCIETY \\ NAVAL WEAPONS CENTER
}

The Supporting Institutions listed above contribute to the cost of publication of this Journal, but they are not owners or publishers and have no responsibility for its content or policies.

Mathematical papers intended for publication in the Pacific Journal of Mathematics should be in typed form or offset-reproduced, (not dittoed), double spaced with large margins. Underline Greek letters in red, German in green, and script in blue. The first paragraph or two must be capable of being used separately as a synopsis of the entire paper. The editorial "we" must not be used in the synopsis, and items of the bibliography should not be cited there unless absolutely necessary, in which case they must be identified by author and Journal, rather than by item number. Manuscripts, in duplicate if possible, may be sent to any one of the four editors. Please classify according to the scheme of Math. Rev. Index. to Vol. 39. All other communications to the editors should be addressed to the managing editor, Richard Arens, University of California, Los Angeles, California, 90024.

50 reprints are provided free for each article; additional copies may be obtained at cost in multiples of 50 .

The Pacific Journal of Mathematics is published monthly. Effective with Volume 16 the price per volume (3 numbers) is $\$ 8.00$; single issues, $\$ 3.00$. Special price for current issues to individual faculty members of supporting institutions and to individual members of the American Mathematical Society: $\$ 4.00$ per volume; single issues $\$ 1.50$. Back numbers are available.

Subscriptions, orders for back numbers, and changes of address should be sent to Pacific Journal of Mathematics, 103 Highland Boulevard, Berkeley, California, 94708.

PUBLISHED BY PACIFIC JOURNAL OF MATHEMATICS, A NON-PROFIT CORPORATION

Printed at Kokusai Bunken Insatsusha (International Academic Printing Co., Ltd.), 270, 3-chome Totsuka-cho, Shinjuku-ku, Tokyo 160, Japan. 


\section{Pacific Journal of Mathematics}

\section{Vol. 40, No. $3 \quad$ November, 1972}

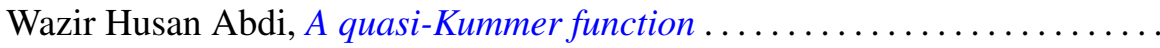

Vasily Cateforis, Minimal injective cogenerators for the class of modules of

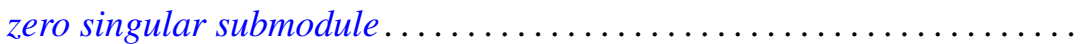

W. Wistar (William) Comfort and Anthony Wood Hager, Cardinality of

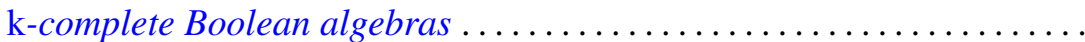

Richard Brian Darst and Gene Allen DeBoth, Norm convergence of martingales of Radon-Nikodym derivatives given a $\sigma$-lattice ..........

M. Edelstein and Anthony Charles Thompson, Some results on nearest points and support properties of convex sets in $c_{0} \ldots \ldots \ldots \ldots \ldots$

Richard Goodrick, Two bridge knots are alternating knots .

Jean-Pierre Gossez and Enrique José Lami Dozo, Some geometric properties related to the fixed point theory for nonexpansive mappings ..........

Dang Xuan Hong, Covering relations among lattice varieties .............

Carl Groos Jockusch, Jr. and Robert Irving Soare, Degrees of members of $\Pi_{1}^{0}$

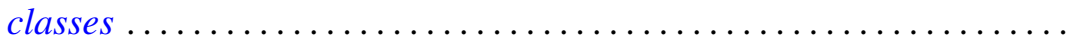

565

575

605

Leroy Milton Kelly and R. Rottenberg, Simple points in pseudoline

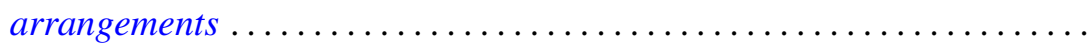

Joe Eckley Kirk, Jr., The uniformizing function for a class of Riemann surfaces....

Glenn Richard Luecke, Operators satisfying condition $\left(G_{1}\right)$ locally ... 629

T. S. Motzkin, On L $(S)$-tuples and l-pairs of matrices ... . .

Charles Estep Murley, The classification of certain classes of torsion free

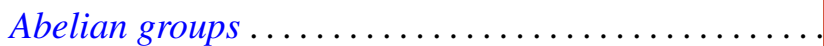

Louis D. Nel, Lattices of lower semi-continuous functions and associated topological spaces.

David Emroy Penney, II, Establishing isomorphism between tame prime

knots in $E^{3}$. . .

Daniel Rider, Functions which operate on $\mathscr{F} L_{p}(T), 1<p<2$

Thomas Stephen Shores, Injective modules over duo rings ...

Stephen Simons, A convergence theorem with boundary. .

703

Stephen Simons, Maximinimax, minimax, and antiminimax theorems and a

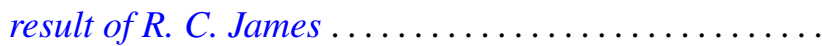

Stephen Simons, On Ptak's combinatorial lemma ........

Stuart A. Steinberg, Finitely-valued $f$-modules............

Pui-kei Wong, Integral inequalities of Wirtinger-type and fourth-order

elliptic differential inequalities .

Yen-Yi Wu, Completions of Boolean algebras with partially additive

operators ..................................

Phillip Lee Zenor, On spaces with regular $G_{\delta}$-diagonals . . . 